Neveen Diaa El-Deen Al-Qassaby

\title{
Poem as a Picture: Eduardo Kac's Digital Poetry and the Interdisciplinary Relationship Between Holographic Media and Literature
}

\section{Neveen Diaa El-Deen Al-Qassaby}

\begin{abstract}
:
This study expounds the symbolism of Eduardo Kac's digital poetry in the context of N. Katherine Hayles' review of electronic literature and W.J.T. Mitchell's image analysis. This accounts for Willard Bohn's study of visual poetry which stages images in the form of letters. The American Poet/ artist Kac (1962 -) departs from the traditional poem and experiments with types of digital poetry like holo-poetry and bio-poetry. Some of Kac's digital poetry is reviewed in Media Poetry: An International Anthology (2007). Philippe Bootz differentiates between what he calls the transitoire observable which refers to a factual depiction of the image in the outer world and the reader's indepth analysis. From this standpoint, Kac's artistic pieces show how electronic literature maintains a manipulation of the digital apparatus in order to redefine standards of the literary work. Mitchell develops the study of iconology which is concerned with the image meanings in themselves, and in their relation with the written word or the pictorial text and other visual media. In picture theory, he divides his study of pictures into three sections; namely "The Pictorial Turn," "Metapictures," and "Beyond Comparison". As a key example, in "Metapictures," Mitchell analyzes three forms of pictures or picture as a reflection of itself, picture within picture and picture in the written text. Through analyzing selected digital poems by $\mathrm{Kac}$, the researcher gives an innovative dimension to the literary experience.
\end{abstract}




\section{القصيدة كصورة: الثعر الرقمي لإدواردو كالك والعلاقة البينية}

\section{بين الأدب وتقتية التصوير التجسيمي (التهولوجروام التوام) الملخص العربى التصوير}

يتناول البحث بالدر اسة والتحليل تيارًا هامًا من تيار ات الأدب الرقمي وهو الثنعر الرقمي

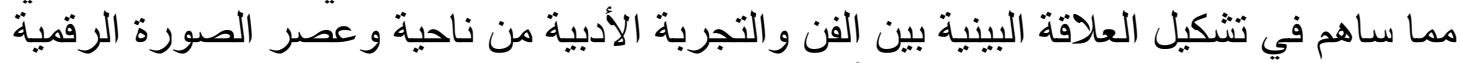

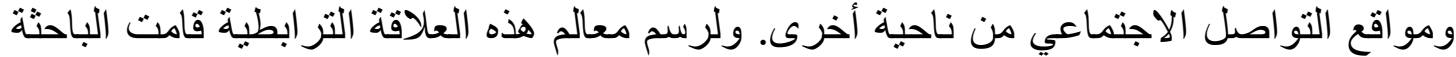

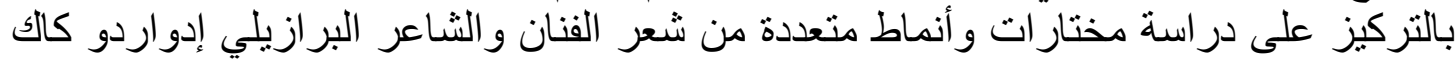

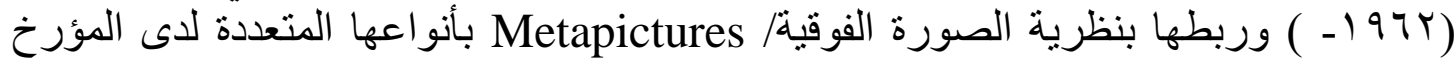

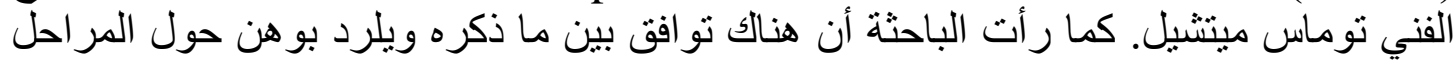

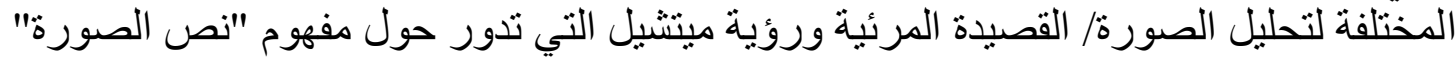

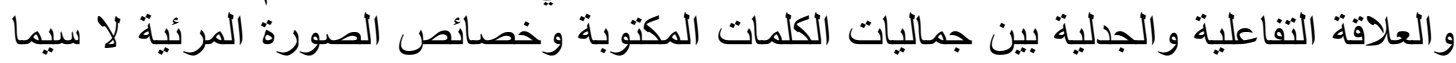

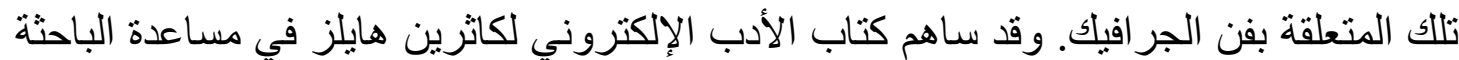

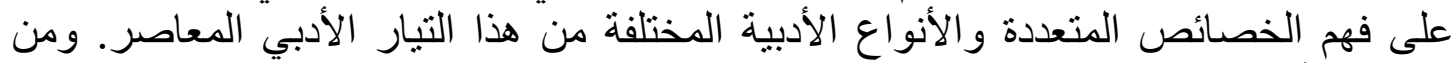

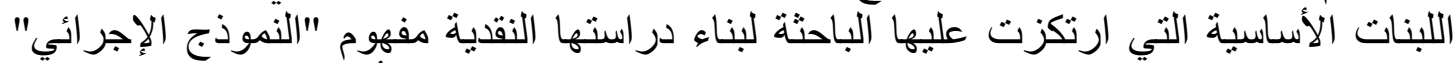

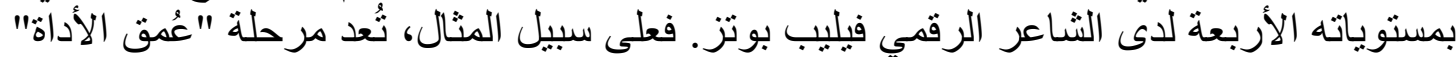

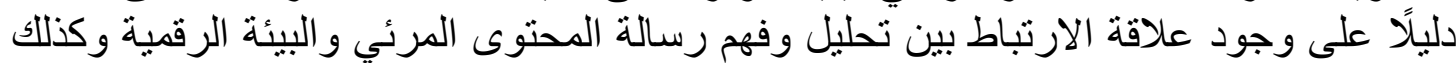

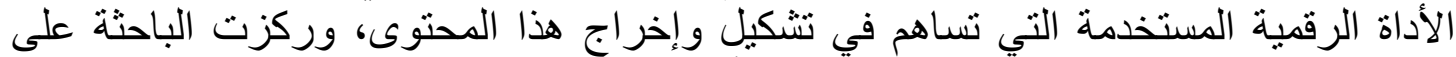

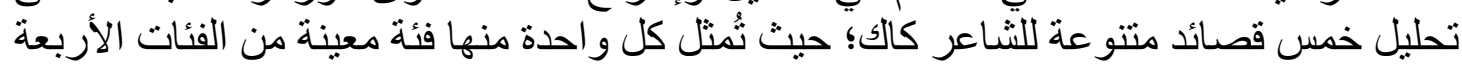

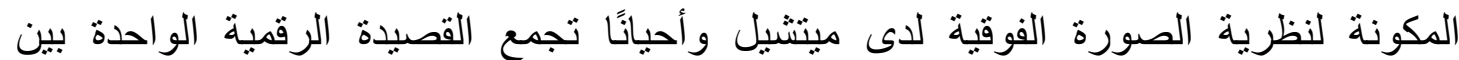

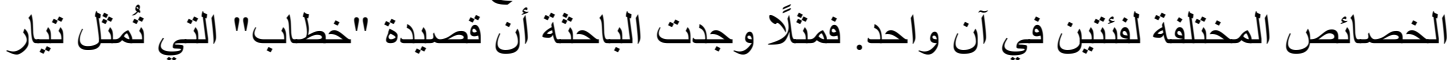

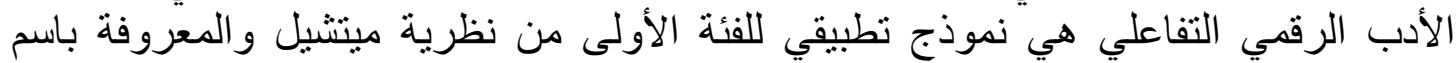

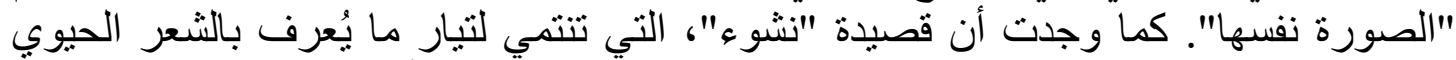

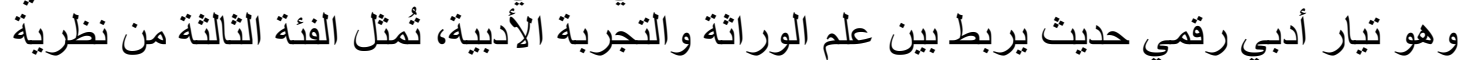

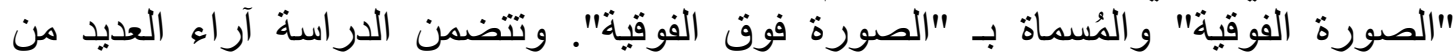

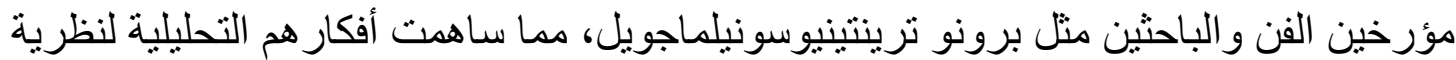
"الصورة الفوقية" على إثر اء البحث وتعضيض أفكار الباحثة النقدية. 


\section{Paper Objectives:}

Studying Eduardo Kac's digital poetry, which is a main branch of visual verse, the researcher expounds the aesthetics of literature in the light of W.J.T. Mitchell's views on Picture Theory. The art historian Willard Bohn, traces the history of visual poetry which has been acknowledged as a form of pictorial literature or ekphrasis in 1978. In his artistic literary approach to visual poetry, Bohn analogizes texts and images. The latter are thought of as the "imagetext" synthesis which Mitchell conceives in his study of images (83). Bohn stresses that "[a]lthough it assumes a great many forms, it inevitably possesses a pictorial as well as a verbal aspect. Combining poetry and painting, the genre presupposes a viewer as well as a reader" (13). In order to decode and interpret the message of a picture/ a visual poem, Bohn believes that there are three main stages which the observers should recognize. Basically, a visual perception of the structure of a pictorial poem, comparing it to other visual objects, helps the observers to realize its symbolic connotations. A second main point is that, they should have a schematic approach so as to analyze a picture's poetic context. This analysis methodology can be related to word typography style, movement of words, picture rotation and text direction. Finally, the observer relies on his mind's eye and the verbal-visual interplay or the dialectical unity between images and words, which Mitchell advocates, so as to deduct the hidden message of a visual poem/ picture.

Giving some reflections on the contemporary literary genre of electronic literature, the researcher delves into the nature of Mitchell's metapictures so as to analyze the inherent poetic language of Kac's pictures/ digital poetry. Hence, the researcher briefly reviews Katherine Hayles'Electronic Literature in order to be acquainted with the major features of the computer literary works and to grasp the spirit of some of the forms of digital poetry like biopoetry and holopoetry. In Media Poetry, Kac stresses that poetry should reflect the modern advances of the digital age but keeps the poet's individual viewpoint. In order to explain the poetic discourse of Kac's pictures selected in this paper, the researcherstudiesMitchell's four categories of metapictures. Defining a metapicture, Mitchell states that it "looks at pictures "as" theory, as second- order reflections on the practices of pictorial representation; it asks what pictures tell us when they theorize (or depict) themselves" (9). Each chosen picture belongs to one or two of the discussed four categories of metapictures. It is the observer's decision whether a picture 
remains as it is or it gives rise to a discussion of metapictures. Consulting the views of a number of scholars and art historians such as Bruno TrentiniandMatthew Ancell, the researcher supports her poetry analysis of Kac'smetapictures/ digital poems.

N. Katherine Hayles defines electronic literature, expounding some of its diverse forms and thereby the literary, material incarnations of the genre. Hayles stresses that in modern times the popularity of electronic literature supersedes the traditional print texts. Hence, there is an interdependent bond between the rise and emergence of electronic literature and the development of computational technology. Therefore, among the multiple questions which the author asks is:how this innovative literary tradition has an effect on the cultural convention. Given a definition by the electronic literary organization, the electronic literary text is "framed to include both work performed in digital media and work created on a computer but published in print .." (Hayles 3). Thus, Katherine Hayles and the poet Pequeño Glazier believe that electronic literature is a form of experimental writing which rejects the narrow, egotistical perspectives and permits the creation of unusual verbal and visual combinations. In ElectronicLiterature(2008), Hayles perceives a kind of hybridity in most of the pieces of digital literature. This is due to an interrelationship between the traditional medium of words, print styles and graphic art. The introduction of elements of mass culture like digital graphics, media forms and online games to the digital literary work manifest an image of this hybridity. Therefore, in some of the digital literary works of the Electronic Literature Collection, there is a junction between letters or words and holography graphics, while some other works are performance-based pieces. Hayles asserts that the digital literary works are "creative artworks that interrogate the histories, contexts, and productions of literature ..." (4). Being a product of culture and due to the influence of the literary movements, electronic literature has moved towards the literary domain, though it does not forsake its concern with digital priorities.

The researcher elucidatesthe main features of other genres of electronic literature, so as to highlight an interactive relationship between the use of digital media and the traditional medium of printed text (print styles). The poet Philippe Bootz is a leader of Generative literature, maintaining the use of algorithm which is a computer-based program so as to combine related words and thereby constitute a text or an algorithmic poem. Moreover, code work is a main genre of electronic 


\section{Neveen Diaa El-Deen Al-Qassaby}

literature which shows a nexus between the computer revolution and print media in a process similar to the art of Cryptography.Giving the example of Perl poems, Hayles emphasizes that "[r]eplete with puns, neologisms, andother creative play, such workenactsa trading zone in which humanonly language and machine-readable code are performed as interpenetrating linguistic realms" (21). Furthermore, flash poetry is another major genre of electronic literature which fosters an interaction between software technologies and textual language. Brian Kim Stefan and Robert Kendall introduce short-sized poems which celebrate this verbal-visual collaboration in flash poetry. Thus, electronic literature carries on the beat of the contemporary digital culture and its effect on the various life domains. With an expertise in digital graphics, computer technologies and creative media, the literary electronic text gives literature a new digital spirit.

Kac has experimented with innovative media apparatus to devise the construct diverse digital poems. Precisely, reviewing his media works, the reader/ viewer will sense the poetics of interactive poetry ${ }^{(1)}$ holopoetry, biopoetry, and hyperpoetry. The main thematic aspects which set the aesthetics of his digital poems are "the conscious symmetry and mechanical precision stress[ing] the seriousness of the poetic enterprise" (Bohn 143). For instance, in many of his holopoems like "Reabracadabra" (1985), the laser/ holographic colours unite the main themes of the media poem which centre around the idea of poetic creation or the stages of creation. Each time the viewer/ reader observes the scattered holographic letters/ shapes constituting the poem's title, he/ she can understand new aesthetic meanings in the animated poem. Thus, Kac transforms the alphabets into colourful iconic symbols. He "extend[s] the solubility of the sign to the verbal particles of written language, the letters themselves, widening the gamut of rhythms and significations of the text" (Kac, "Holopoetry" 135). According to the researcher a notable example of digital poetry is the video poem "Reversed Mirror" (1997), which analogizes the illusive photons maintaining colour changeability to the illusive nature of reality. In addition to the use of an electric piano which generates repetitive music thus enhancing an aesthetic interpretation of this poem, the use of colours has a meaningful role. The dissolution of gray shapes into a white background refers to the process of language construction. Though language generates a momentary nature of feelings, words which revive the experience remain in man's brain.

Kac's interactive poetry reveals that the use of media technology can help the observer to figure out poetic messages. Kac's "IO" (1990) is an 
interactive, three-dimensional, navigational poem which shows that letters or shapes can be verbalized into diverse themes. As an interactive poem " $[\mathrm{t}]$ he reader is invited to explore the space (up/ down, left/ right, forward/ backward) created by the stylized letters and experience it both as an abstract environment and as a visual text" (Kac, "From ASCII to Cyberspace" 55). The mobile 3D figures, "I," "O" and the letter I transformed into ribbon-like shapeswhich constitute the poem's main object invoke a number of readings. In"From ASCII to Cyberspace,'Kac points out that in Italian "IO" means the subject pronoun "I" so the poem can be interpreted as a depiction of a narcissistic personality or an egotist (55). Another reading advocates reconciling differences between self "I" and other "O". Even the metamorphosis of the "I" into a twisting image of a ribbon supports human connections between people. Another example of an interactive, Kinetic poem is Kac's "Secret" (1996) which revolts against the normal reading position. Displayed on a computer screen " 'Secret' adapts the mimetically biased technology of VR to represent the material typographic sign, the symbolic letter, the word, and other units of writing as three-dimensional objects in space ..." (Lennon 260). The words that float in a virtual space are "wind/ that blows/ within/ sail away/ like/ tranquil thunder" (Ibid., 261). Since the reader/ viewer can read, in any position, the graphic words/ images, Kac's poem stimulates the two phenomena of fluid signs and multistable perception. Fluid signs are discussed in the part which the researcher devotes to analyse two of Kac'sholopoems. There are different possible analyses of this media poem. The first one is that man's ideas are changeable with the passage of time. A second reading discloses a fusion of any two contradictory beliefs or thoughts inside man's head. Finally, Kac's main message is that the technological and scientific revolution leads to cultural changes.

Kac'sholopoems and Bio art projects elucidate the aesthetic experience of his poetry. Besides experimenting with video and computer-based technology, Kac's bio art projects show how the science of genetics and quantum physics can generate and expand the poetic experience. For instance, in "Genetics" which the researcher analyzes in this poem, Kac transforms words into genetic codes. As a biopoem project, Kac's "AsyntacticalCarbogram" shows that nanodots can revolutionize the aesthetics of poetry writing and traditional language. In this project Kac aspires to prove that "[1]etters can be created with carbon nanotubes, tiny cylinders only a few billionths of a meter in diameter, as exemplified by this letter " $T$ " " ("Biopoetry" 195). The picture of the 


\section{Neveen Diaa El-Deen Al-Qassaby}

letter " $T$ " stands for this new nano language of poetry. Kac'sholopoem "Multiple" (1989) manipulates the holographic feature of parallax. Furthermore, in this holopoem the metamorphosis of the numbers " 3309 " into 3D shapes of the word poem pertains to the typography effect of fluid sings. Reviewing some electronic bibles and dictionaries like Bible Hub and StudyLight, the researcher elucidates that in Greek language and a number of scriptures the code "3309" stands for anxiousness. The aesthetics of this calligraphy poem "translates a characteristic of the Hebrew alphabet (in which letters also stand for numbers) into the Latin one" (Kac, "Holopoetry" 145). Kac urges the observer to be anxious to know the hidden themes in this holopoem. In the holopoem "Chaos" (1986) pseudoscopic and binocular vision give illusory and different perceptions of the graphic letter. Therefore, some "intertextual possibilities may emerge, such as the words "só" and "ossos" ("alone" and "bones" in Portuguese, respectively)" (Kac, "Holopoetry" (138). Obviously, the poet urges the viewer to imagine the consequence of a mechanical life which an isolated man leads. In other words, the technological facilities enhance the chaotic misery of man's loneliness.

The image aesthetics of Kac'shyperpoem "Storms" (1994) elucidates some of the peculiar features of digital poetry and urges the viewer to undergo a process of a picture analysis. In an interactive process, the viewer is invited to navigate the computer screen to constitute different lexical units. Scrolling and navigation show that " $[t]$ he reader is now presented not with one narrowed-down selection of words in strings or in graphic layouts, but with an electronic field that is a complex network with no final form" (Kac, "From ASCII to Cyperspace" 57). The strings of consonants and vowels from a picture of a Kabbalistic tree of life. The nodes of this digital tree create a multistable picture. Moving across the cyperspace of this hyperpoem enhances the multistable phenomena and thematic diversity. Kac believes that the poem invokes a mystical experience of poetry which is equivalent to elements of Kabbalah/ Jewish mysticism. Focusing on five of Kac's digital poems, the researcher relates her in-depth thematic analysis to a discussion of Mitchell's picture theory and Bootz's stages of the procedural model.

In the "Pictorial Turn," Mitchell believes that living in the image culture, there is an obsession with images as discourse and knowledge of iconology. Ludwig Wittgenstein's philosophy sets the methodology of a belief in this pictorial supremacy. His ideas elucidate that the persistent repeatability of images, which is similar to that of language,leadsto a form of picture thinking. Like linguistics, pictures have become a field of 
study, simply because a picture can refer either to itself or to other pictures and can have connotations to other branches of knowledge. A close analysis of a picture shows that it has its peculiar language which can be verbalized into a comprehensive text. Mitchell adds that the pictorial turn is "a postlinguistic, postsemiotic rediscovery of the picture as a complex interplay between visuality, apparatus, institutions, discourse, bodies and figurality" (16). Therefore, reading a picture is similar to the cognitive process of text decodification and the different levels of textual analysis.

Mitchell's definition of the pictorial turn proposes that a discussion of the difference between picture and image is inseparable from the interplay between the verbal and visual domains. Image stands for the content or the message which needs an outer framework or a picture to accentuate its existence. Though a picture is somewhat perishable, both image and picture cannot exist in separation. This hints to Mitchell's notion of the "imagetext" (83) which shows an interdependent relation between the written word and the visual media. Hence, Mitchell's pictorial turn "investigates the interactions of visual and verbal representation in a variety of media, principally literature and the visual arts" (4-5). Though it appears that there is peripheral separation between images and texts, this turns to be untruthful. This is because almost all the fields of knowledge involve a visual manipulation which can be verbalized into language.

Mitchell believes that analyzing an image is a complex, multiple process that is based on an awareness of the existence of a new observer and the digital techniques which maintain the image production and affect the perception. Mitchell cites Jonathan Crary'sTechniques of the Observer (1990) discussing the idea that due to the advancement of the image culture, the nineteenth-century viewer has become part of a whole technological institution, therefore his vision is rather subjective. Furthermore, in "The Pictorial Turn," Mitchell introduces Panofsky's figurative example of two men greeting each other to elucidate the developmental stages of image analysis. Mitchell's main concern is with a "transformation of this simple, social encounter (the men passing in the street) into the encounter between a subject and an object (the perception and "reading" of an image, a painting) and finally into the encounter between two "objects" of representation" (26-27). This ordinary scene explains the process of an image-formation and promotes an inductive approach so as to realize the symbolic connotations of an image/ object. 


\section{Neveen Diaa El-Deen Al-Qassaby}

Rather than substituting the linguistic medium, the pictorial turn depicts an analysis of the verbal discourse of an image.

Mitchell explains the methodology and conditions which constitute metapictures and their different forms. Defining metapictures, Mitchell states that they are "pictures that refer to themselves or to other pictures, pictures that are used to show what a picture is" (35). In other words, a metapicture urges a viewer to realize that a picture explains the conditions of its creation. Being self-referral, it is the viewer's role to decipher and recognize a picture's historical epoch and its connotative meanings without depending on textual explanations or any form of a second-order conditioning and representation. Discussing the first category of Mitchell's metapictures, a picture refers either to itself or to the art of picturing. Mitchell contends that there should be two analyses of the same picture, and the distinctions between its inner and outer borders should not exist, having a free boundary so as to maintain a metapicture. Being conceived as a picture which exists inside another one, metapictures can also refer to other images. In "The Meta as an Aesthetic Category," Bruno Trentinithinksthat the observer's subjective viewpoint is the criterion which determines whether a picture remains just as it is or it can be elaborated into a metapicture.

Giving two examples from The New Yorker, Mitchell differentiates between the main two forms of self-referential pictures. As an example of the first form in which pictures comment on their content and explain the process of their making, Mitchell outlines different analyses of Saul Steinberg's art work, The Spiral (1964). Reading the chapter "Metapictures," Mitchell outlines that the two basic analyses of this drawing are based on the direction of the spiral, whether it moves inside towards the man or outside to the outer world. In case of the first movement of the spiral, the picture is of a man of leisure who scratches circle lines just to spend his time. Considering the second direction of the angle, the man is an artist who is creatively drawing a new world, an outer world which voices the spirit of the contemporary visual culture. Other two possible interpretations are related to the art of painting. The first is a symbolic indication of a modern aesthetic approach of the schools of Abstract Art. The second shows an interplay between the verbal and the visual and maintains an instance of Mitchell's imagetext. Thus, it "shows another [art] history, one that has moved from the figure to abstraction to landscape to the writing at the bottom - to a "New World" that lies beyond the circumference of the drawing" (Mitchell 40). The main factor which maintains that it is a metapicture is a dissolution 
between the inner and outer boundaries.Reviewing Brain Stefans's "The New Commodity,"headds that in case of a metapicture, the real scene becomes part of the image world, but they cannot be considered as one, as they remain in a state of continuous transitions. Stefans asserts that "[i]n a metapicture, the "real" is denoted as transitioning into the "image," but the horizon between the two is blurred-the real and the image don't collapse into a single, stable whole but are situated along a continuum, the break in which is indiscernible" (76).

Expounding the main features of self-referential pictures, Mitchell discusses the second main form of this category in which a picture refers to a couple of other images or to the genre imagery. Mitchell tackles Ernst Gombrich's viewpoint of Alain's picture, "Egyptian Life Class," so as to be taken as an emblem of the developmental stages of art history and the art of photography. The two main readings of this picture contribute to the method of dialectical argumentation. They create an experience of a metapicture which "is not reducible to one reading or the other but is constituted in the argument or dialogue between them" (Mitchell 45). Gombrich's thesis is that the Egyptians portray their stereotypical images of nature, therefore their painting model differs from the Western one. However, Mitchell has an alternative analysis which stresses that the Egyptians do not have a different perspective but rather they act in much the same way as all students in painting classes. Hence, the two dialectical interpretations of this metapicture help the observer to deduct the main message of this picture which comments on another one of an Egyptian female nude figure.

Mitchell's second category of dialectical or multistable images can be viewed either as two images existing in one or as one image. Sunil Manghani stresses that "a 'meta' analysis requires a picture to present more than one point of view at the same time" (183). "The Duck-Rabbit" is an iconic image which acts as an example of multistable perception. Mitchell asserts that "[i]f the multistable image always asks, "what am I?" or "how do I look?," the answer depends on the observer asking the same questions" (48). W.J.T. Mitchell and Christoph F.E. Holzhey believe that multistable images raise into consideration the concept of the mind's eye. Expounding the nature of multistable images Mitchell observes that the viewer's subjective perception and his mental thoughts can determine whether he sees a rabbit or a duck. Thus, "The Duck Rabbit" expounds a self-referential explanation to the context of human subjective perception. 
Mitchell's third category of pictures, "A Meta-metapicture," which is discussed in the chapter "Metapictures," is depicted as self-referential not to itself or to other pictures but to the concept of picturing and to the theory of representiation. Velázquez's Las Meninas is concerned with the types of vision. In other words, it addresses whether the viewer remains in his position outside the picture or he undertakes the role of the artist and becomes part of the picture in a mirror reflection. "It is the painting's ability to destabilize the position of the observer" (Michell 63). A view of objects is changeable or inconsistent, therefore the painting captures the viewer in a play of unlimited referentiality. Moreover, the viewer can partake in the pictorial scene, thus taking on different roles as in the context of the royal family. The observer's perception determines whether the mirror reflects the child image or that of the viewer who can take the role of the child. GayanaJurkevich and José Antonio Maravall believe that the mirror has a pivotal role because it can transpose an outer scene or figures to be part of the inner world of the picture. Jurkevich stresses that "Velázquez's partial vision from within the painting, and the mirror on the backwall whose function is to restore visibility to the focalizer(s)" are the main features of this picture (93). What sets Las Méninas to be considered as a metapicture is the position of the viewer who is neither considered as part of the picture nor excluded outside it. Hence, Mitchell epitomizes that "Las Meninasis an endlessly fascinating labyrinth of reflections on the relations of painting, painter, model and beholder" (58).

Michell's composite of image/ text ${ }^{(2)}$, with the use of a slash, is representative of the fourth category of metapictures, "Talking Metapictures" which shows a difference between the verbal and visual dialectics. He gives René Magritte's Les trahison des images/ The Treachery of Images (1929) as an example of a "gap between words and pictures" or a space in the relationship between what is seen and what is said (Mitchell 65). The caption is in complete separation from the visual picture. However, the discourse elements constitute a state of selfreference either to themselves or to a unit of the verbal and the visual. Though the words are indifferent to the image, a text comprehension requires a systematic study of them together. Andrew Coates elucidates that "Magritte's image emphasizes the hollowness of words and the inadequacy of our systems of representations" (21). There are two main interpretations of the picture. One of them gives precision and accuracy to the meaning of words, while the second defends the image. Hence, the words which indicate that "this is not a pipe" are truthful and logical because after all it is just a picture and not an object/ pipe. However, the picture can be connotative of the viewer's perspective, realizing the 
existence of a pipe in the real world. Hence, this fourth category of metapictures, which include other two examples one of them is of Richard Williams" "Nude Beach," a front cover of Mad Magazine, gives the viewer a teaching lesson. Examining the contradiction between the verbal and the visual elements, the viewer should not be deceived by appearances/ systems of knowledge.

In "Beyond Comparison: Picture, Text, And Method," Mitchell emphasizes his concern with the imagetext synthesis as a method of study. Therefore, Mitchell is neither concerned with verbalizing an image's verbal discourse nor with observing a text's various visual elements but rather he stresses the verbal-visual integration in the same work of art/ picture. Hence, Mitchell eliminates the differencies between what he describes as " "pure' visual representations" and " "pure' texts" which should not exist (95). This accounts for a discussion of the three different forms of the word-image relationship. Mitchell contends that "the slash [is used] to designate "image/ text" as a problematic gap, cleavage, or rupture in representation. The term "imagetext" designates composite, synthetic works (or concepts) that combine image and text. "Image-text," with a hyphen, designates relations of the visual and verbal" (89). Introducing an imagetext synthesis, he formulates a dialectical unity between the two which can be used as a basis for the comparative techniques between images (art) and texts (literature). An image involves visible or audible discourse and poetic words/ literary language even though they seem to be unobvious and intangible to the observer.

In his discussion of holopoetry and biopoetry, Bootz differentiates between multiple stages in the process of reading/ writing a digital poem. There is a main difference between the author-reader relationship with the text. "Texte-auteur" refers to the special relation between the author and his text (Bootz, "Programmed Digital Poetry" 48). As a text producer, he can encrypt certain codes/ signals in the digital text which are recognizable for him. "Text-avoir" hints to the reader's subjective viewpoint of the perceived text (Ibid). Discussing the "profondeur de dispositif"/ the apparatus depth, it indicates the reader's mind analysis of codes (Ibid., 47).

By the depth of the device, Bootz implies that there is a built-in relationship between the digital or computer apparatus, the cognitive faculties, digital symbols and multimedia message. It is a comprehensive process which requires an integration between the digital device/ 
computer and human faculties so as to recognize the meaning of the digital image. "The apparatus depth is the set of archetypal cognitive representations a player resorts to in the system in order to create meaning" (Bootz 47). Hence, the significance of a multimedia content cannot be understood in separation from its digital context/ environment and the digital device which generates it. The depth of the device is part and parcel of another consecutive stage/ level known as the "transitoire observable" (Ibid.,48).Hence, the two stages complement each other. The depth of the apparatus stimulate the reader's cognitive abilities in the attempt to deduct the symbolic connotations of the fleeting multimedia signs/ content.

One of the main stages of the procedural model which Bootz analyzes is called the transitive observable. It stands for a transitory multimedia phenomenon which is seen on a computer screen and is computer generated. Cognitive thinking transforms this ephemeral content into a visual/ textual message. Bootz states that "[a]transitoire observable is the physical event the reader perceives (or experiences) ... . It can be recorded with a device (e.g., a video system) and then does not constitute a sign, but rather a signal or an object" (Ibid). Bootz uses this term to stress that multimedia messages or digital sign systems appear and disappear. In other words, they are fleeting and changeable, therefore the reader's cognitive abilities help him to remember and analyze the multimedia content which he views and senses.

In the 1980s, Kac has experimented with the digital techniques, and the computer domain, introducing an innovative media poetics which liberates poetry from the traditional lexical rules. Being a product of the computer technology and video capabilities, the observers have difficulty in deciphering the meanings and the cultural context of a digital poetic work. Therefore, they have to analogize its somewhat complex construct to the outer world structures. However, this dualism of the digital and real worlds creates the the hidden literary language of a digital poem. Stressing the poetics of digital media ${ }^{(3)}$, Kac "develop[s] an immaterial poetry for the information age; that is, poetry native to the new cultural environment of digital global networks, with its dynamic data flux and distributed communication systems" ("From ASCII To Cyberspace" 45). Whether displayed on the internet or in a digital exhibition, Kac's media poetry foreshadows a dialogue between literature and image. Hence, media poetry stimulates the observers' sensory learning styles in the attempt to understand the connotations/ themes of a digital/ holographic 
poem. Kac's digital poetry proves that the use of media boosts the modes of creative immagination, thus generating a poetic image.

As an example of interactive poetry, which is one of the main forms of digital verse, the researcher believes that "Letter" represents the first form of Mitchell's self-referential metapictures "The Picture Itself". Analyzing the digital image, it shares many features with the model of Saul Steinberg's The Spiral (1964). Moreover, being an interactive poem, the experience of its poetic analysis accords with Bootz's account of the "text-ávoir"/ the text to be seen in the procedural model (48). Therefore, each reader/ viewer can have his/ her own subjective interpretation of this picture. This stimulates a discourse on it as "a metapicture in a strict or formal sense, a picture that refers to its own making, yet one that dissolves the boundary between inside and outside, first and second-order representation, on which the metapictorial structure depends" (Mitchell 42). Sticking to Mitchell's paradigm of the metapicture which comments on its creation process or foreshadows an art movement, the researcher observes two basic interpretations of "letter":

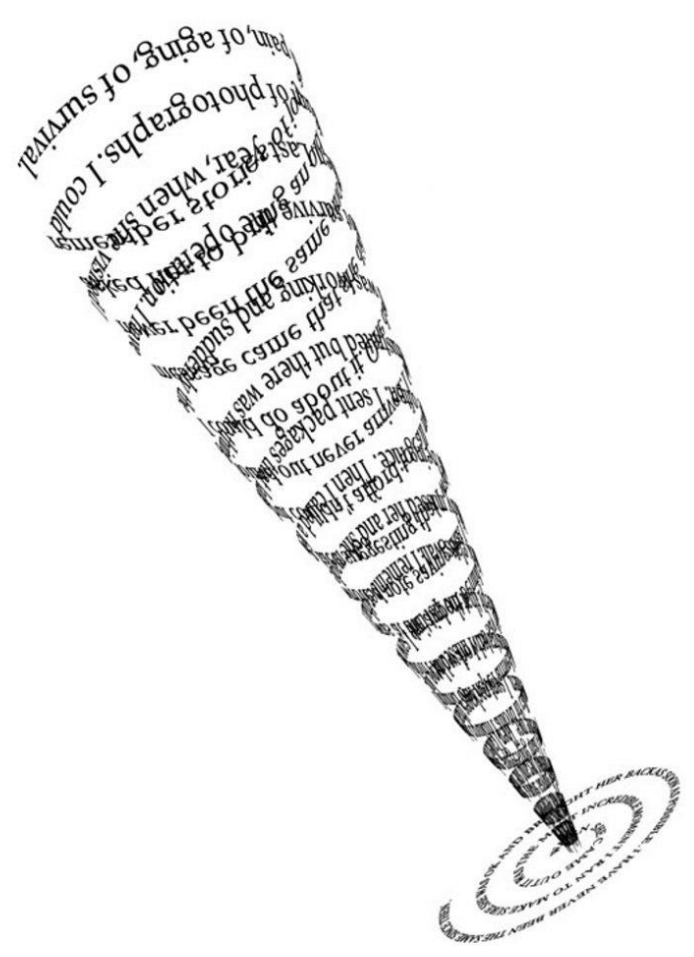

Fig. 1. An interactive poem first displayed on computer in 1996 from: Kac, Eduardo. "From ASCII to Cyperspace". Media Poetry, 1 April 2019, p. 59. 
Being conceived as a trumpet like picture which escalates into a selfreferential metapicture, the analytical approach depends on the eye movement and the direction of the visual angle. The viewer is the one who can read the discourse which the picture says about itself. Trentini further explains that what creates this self-reflectiveness is the observer's cognitive interpretation which becomes part of the picture's world. The researcher believes that "Letter" depicts a stream of thoughts which splash from a trumpet's brass body or a point of nothingness to a conceptual space. Hence, observing this picture in a bottom-up approach, it stands for Mitchell's account of the pictorial turn. The endless flow of letters in circular shapes refers to the repetitive nature of images. Acting as a viewer, the researcher's first interpretation of this picture is that it acts as an emblem of Mitchell's imagetextsynthesis. In other words, the union between painting of circular lines and words can be connotative of an image revolution. The flow of man's thoughts like a river's water pertains to the creation of this contemporary image culture. This is because the narrated personal experience combines both verbal and visual elements.

A top-bottom approach to this picture further reveals the poetic theme and gives a poetry analysis in the context of art history. Trentini believes that the viewer's presence in a picture's world creates a metapicture. He explains that "if they immerse themselves into the picture, they temporarily inhibit the picture qualities of representation in order to apprehend the picture like a nesting presentation" (Trentini 3). In "Letter," the first-person narrative shows that the observer coincides with the poet narrator in the attempt to decipher the poetic message. Reading the poem horizontally from the top, the viewer can read this sentence "Last year, when she visited I could remember stories of joy, of pain, of aging, of survival". (Kac59). The viewer can also read easily the noun photographs and the fragment "survive the operation" (Kac, "From ASCII To Cyperspace"59). He/ She brainstorms ideas, which is analogous to the circular motion of words, in order to reach an end or the zero point and understand the humanitarian message behind the personal 
story. The viewers share with the poet narrator his love for a female figure who is supposed to carry on an operation. Each one can recall a similar individual memory of his/ her own and participate in the narration of this "letter". Bohn adds that "[c]ontaining poignant memories of his grandmother, his mother, and his daughter, "Letter" celebrates their existence, past and present" (157). In the context of art history, "Letter" manifests Mitchell's belief thatthe verbal contains visual elements ${ }^{(4)}$ and vice versa. Being a self-referential metapicture, the borders between the two worlds of picture and reality do not exist. Thus, the researcher believes that the circular movement of memories which becomes part of the poem's structure is in a state of flux. Therefore, they extend in a circular movement from the world of the picture/ the artist to that of the viewer and maintain a unity between semantic representations of the poem.

In order to incarnate the main poetic theme of "Letter," there is an inherent relationship between this interactive poem's structure and Bootz's the depth of the device. Bootz gives a main concern to the role of the digital device/ computer in the meaning analysis of a digital work. For instance, the structure of a digital poetic work can reflect the design of the digital apparatus used to produce it. Therefore, an observer should maintain his mental faculties so as to realize the symbolic significance of the digital content with regard to its digital world/ context. The researcher perceives that "Letter['s]" structure can either hint to the use of vector graphics so as to create abstract technology circles or to Leo Tolstoy's belief in the body machine. In War and Peace, Tolstoy states that "[o]ur body is a machine for living. It is organized for that, it is its nature. Let life go on it unhindered and let it defend itself, it will do more than if you paralyze it by encumbering it with remedies" (1110). Attacking culture, Tolstoy believes that an innovative art work which is produced in detachment from culture constrains is a means to achieve immortality. Caryl Emerson and InessaMedzhibovskaya explain that for Tolstoy 
"spiritual activity is a lonely process. Whether fuelled by personal memory or by common striving, it always involved stepping outside one's corrupted and automatized aesthetic environment" (27). As a digital artist/ poet, Kac becomes indifferent to the traditional writing styles, therefore the observer/ reader can contemplate "Letter" as a form of the vector circles. Hence, the innovative design of "Letter" can be connotative of its theme. The poem can stand for the tendency of man to revise his memories so as to have his own beliefs which are in discordance with his family culture. The poetry analysis of "Letter," as a self-referential metapicture, is subject to the perspective of each viewer.

Based on a review of metapictures, the biopoem "Genesis," is an iconic example of the third type "Meta-metapicture". One of the main genres of digital verse, which Kac innovatively experiments with, is biopoetry. Being staged in diverse art exhibitions, "Genesis" exemplifies Kac's aspirations for "the use of biotechnology and living organisms in poetry as a new realm of verbal, paraverbal, and non-verbal creation" ("Biopoetry" 191). Clans Clüver refers to this transgenic work as a piece of an intermedia art, maintaing an integration between diverse media forms in its digital environment. Introducing science of genetics to the poetry practice, "Genesis" gives a model of Mitchell's imagetext synthesis, expressing a sense of interaction between the verbal/ visual representations. Kac's belief in a dialogic relationship between the technological manifestations and the literary field sounds clear in this biopoem. Hence, the poet manipulates a use of the computer apparatus and a projector to design the digital production of "Genesis". This accounts for an integration between the researcher's poetry analysis and Bootz's two levels of the depth of the device and the transitive observable in the procedural model. As a meta-metapicture, it is the glimmering Petridish which contains the poetic gene that can maintain a selfreferential formula and project an image of the viewer in the picture's world: 


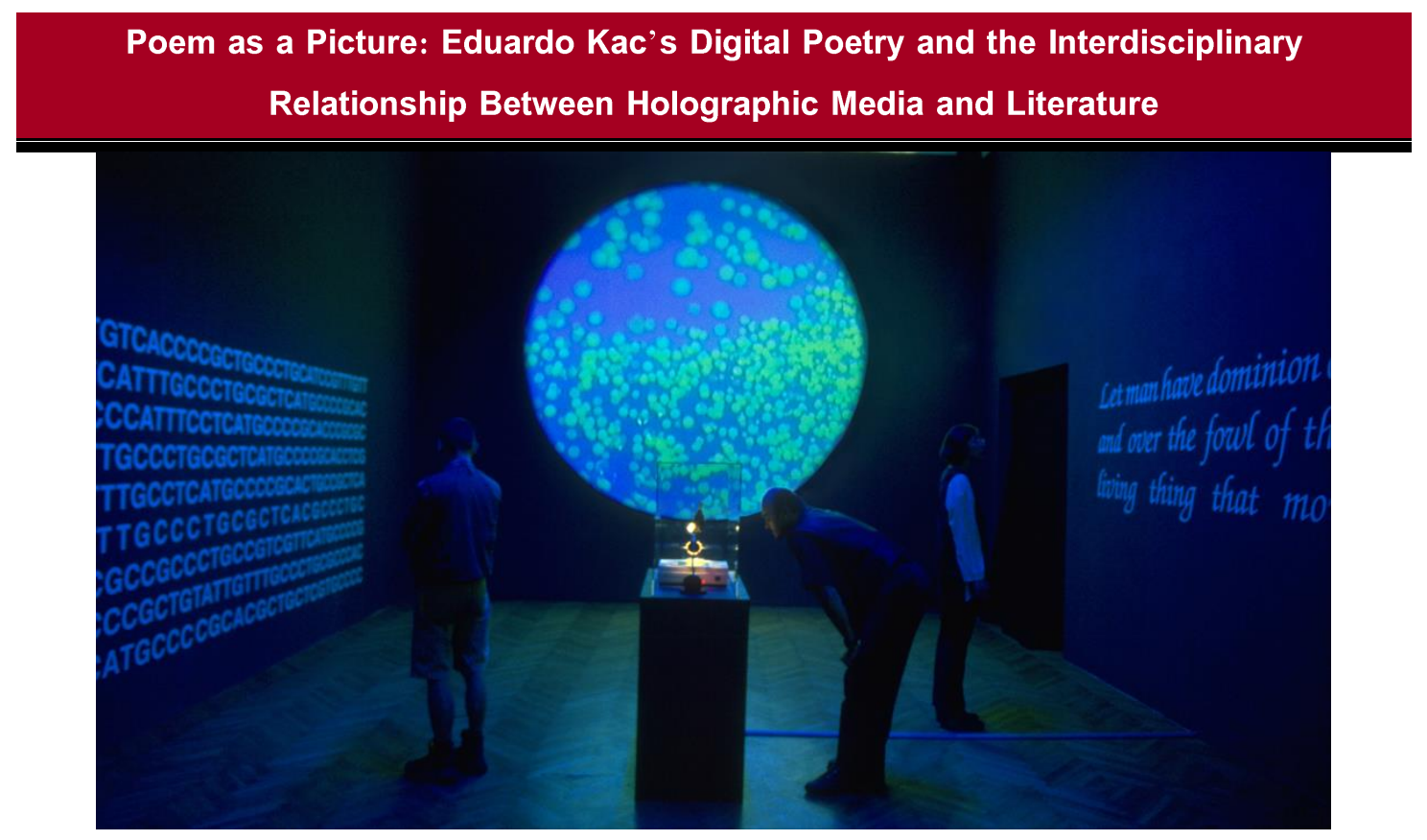

Fig. 2. Kac, Eduardo. "Genesis". 1999, Ok Center for Contemporary Art, Austria. “ 'Transgenic Art': The Biopoetry of Eduardo Kac,” by Clans Clüver, Springer, 2010, https://download.Springer.com/static/pdf/183/bok\%253A978-0-230-275201.pdf?originUr1-/=http\%3A\%2F . Accessed 14 April 2019.

A comprehensive analysis of Kac's "Genesis" and its digital context show that it is structured on the model of Velázquez's Las Meninas. Mitchell stresses that "[t]he formal structure of Las Meninas is an encyclopedic labyrinth of pictorial self-reference, representing the interplay between the beholder, the producer, and the object or model of representation as a complex cycle of exchanges and substitutions" (58). Within the constructed digital environment in the gallery, the two dark walls which display a line of biblical verse advocate the interchangeability of the verbal and the visual. On the right dark wall, the viewer can read the following line from Genesis: "Let man have dominion over the fish of the sea and over the fowl of the air and over every living things that moves upon the earth" (cited in Kac, "Biopoetry" 194). On the opposite side, Kac maintains a genetic transformation of this line, using the Morse code transcriptions. In the middle of the room there is a Petri dish that "contained two kinds of bacteria, both genetically engineered to glow: one kind, which contained the synthetic gene, emitted blue light, the other kind, which did not, emitted yellow light" 
(Clüver 176). The researcher believes that there are symbolic connotations for the choice of the yellow and blue colours. The first one indicates the digital age leadership and the sunrise of the scientific and technological innovation. As for the second, it stands for the colour of water which maintains the life processes of all the living organisms. This colour chart sums up the poetic theme of "Genesis," stressing that man has power over other creatures on earth owing to the scientific and technological advancements. A further discussion of the role of the Petri dish and the symbolic significance of the digital environment can expose the self-referential structure of this biopoem. There is a continuous selfreferential process which oscillates between the viewer/ artist and the two verbal and visual artifacts/ walls ${ }^{(5)}$. In this way, the viewer can take part in the picture's world but remains outside it.

The Petri dish (science) and the projector/ computers (digital apparatus) help to transmit the viewer into the picture's world and to develop an analysis of "Genesis" as a manifestation of the northern descriptive mode which isone of the painting methods. Acting like the mirror in Velázquez's painting, the Petri dish and the projector support the multiplicity of the viewer's roles. To this point, Mitchell comments that "Velázquez gives us a portrait of the artist as servant, holding up a seductive mirror to a beholder who is at once the sovereign, the painter himself, and any passing observer" (63). Like Velázquez's model, the viewer can now imagine himself as one of the living creatures referred to in the picture, a monarch man or as an artist who perceives the outer world and designs the digital event. Matthew Ancell explains how Velázquez's painting can be considered as a model of the northern descriptive mode. Consequently, the researcher believes that Kac's "Genesis" is a reflection of this painting style. In "Genesis," the artist is physically absent because the viewer plays his role, however his presence maybe felt in the depicted digital scene(s). The Petri dish, computers and the projector used in the digital context of "Genesis" give the observer an image of the perceived real world where man as a viewer/ artist can live. 
The self-referential structure of "Genesis" expounds the view that this biopoem/ meta-metapicture is a complete construct of Bootz's procedural model. As for the model of the author-text relationship,Kac utilizes the genetic modification technology so as to realize the metamorphosis of "Genesis" " poetic language. Thus, he makes use of the Morse code transcriptions, constituting a DNA or the visual text of the biopeom. This opens the possibility of giving various interpretations of "Genesis". In this level known as text to be seen, the poetry analysis differs according to the perspective of each viewer and his/ her subject position in the digital universe/ picture's world. In order to maintain the self-referential nature of "Genesis," a projector is used to foreshadow a picture of the DNA and the computer apparatus generates Protein music and stages a live media performance. This foregrounds the role of the depth of the device as a main element which can help the viewer to mentally decode media images or to develop a mind-reading algorithm ${ }^{(6)}$. Being closely connected with the level of transitive observable, it is the reader/ viewer's role to observe the ephemeral media which the computer stages and to relate it to the textual graphic of the Morse Code. Hence, the researcher decodes Kac's poetic message related to the point that the technological evolution transforms man's life. Clüver's discussion of the symbolic significance of the digital environment pertains to a development analysis of self-reference in "Genesis". He states that "[t]he complex sign communicated by this particular laboratory setting is primarily self-referential: it concerns the use of ordinary biological procedures to make us aware of the possibility of genetic engineering through the creation of a gene resulting from particular transformative processes" (Clüver181). However, the researcher believes that this selfreferentiality goes back to the structure of "Gensis" as a metametapicture. Hence, the biopoem does not comment on itself or on another picture but rather it gives a complete episode of self-referential art. Thus, the researcher observes the circular motion of the selfreferential structure of "Genesis". This self-reference starts in the media 
which the computer stages then it moves to the Petri dish and the projector until it reaches the viewer. Before this self-referential structure falls back on the Petri dish and the digital devices, the viewer can either stay in his/ her place or play the roles of a telecommunications engineer, a genetic engineer and a king of the animal world. Kac's digital aesthetics and scientific model set a paradigm of Mitchell's meta-metapictures.

Being performed on a Minitel computer, "Deus"/ "God" is a video poem which the researcher analyzes as one of Mitchell's "Talking metapictures". This animated video poem displays a division between the religious thematic analysis of the noun "Deus" and the visual image of a barcode in which it is written. Taken as an example of Mitchell's image/ text concept, the Minitel animated poem maintains two examples of selfreferential relationships. Hence, the barcode of letters and numbers refers to either itself or the coexistence of an image and a text, even though there is a split between them. Observing the barcode label design, the fragmented letters of the noun "Deus" and the scattered numbers of the two years, 1964 and 1986 cojoin in diverse innovative forms. Kac's experimental poetics shows his tendency "to take the word into photonic and virtual spaces, enable it to have a malleable temporal dimension, and explore features of the verbal so far unthinkable" ("From ASCII To Cyperspace" 46). The different variations of the word "Deus," show a break with the Brazilian Parnassian movement ${ }^{(7)}$ which advocates a rigid literary form. The digital poetics of "Deus" provides reflections on aesthetics and politics: 
Poem as a Picture: Eduardo Kac's Digital Poetry and the Interdisciplinary Relationship Between Holographic Media and Literature
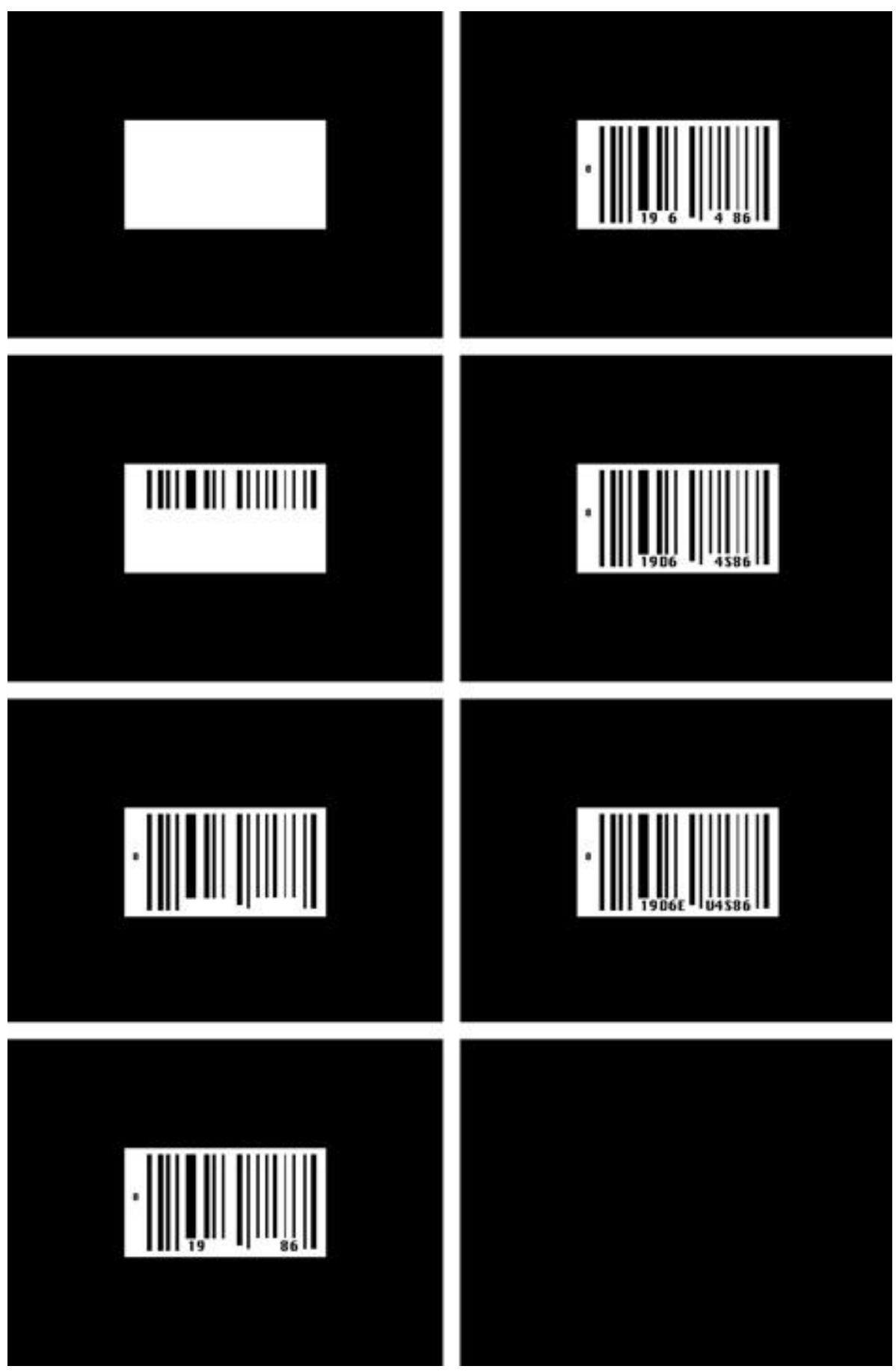

Fig. 3. A Minitel animated poem whose barcodes are displayed horizontally. The poem is shown online in 1986 from:Kac, Eduardo. "From ASCII To Cyperspace". Mediapoetry, 1 April 2019, p. 50. 


\section{Neveen Diaa El-Deen Al-Qassaby}

The digital aesthetic methodology of "Deus" develops a relationship between the features of "Talking metapictures" and political connotations. There is a disparity between the image of the barcode logo which has implications for the industrial revolution and commercialization and the religious context of the noun "Deus". It foreshadows a division between the audible and visual representations and questions the contesting hierarchy of words over images. Mitchell adds that "[i]t isn't simply that the words contradict the image, and vice versa, but that the very identities of words and images, the sayable and the seeable, begin to shimmer and shift in the composition" (68). Though the image of a barcode does not reflect the choice of the noun "Deus," the first reading gives credit to the word. The latter stresses the absolute existence of God's power, and presumes that this videotext poem has religious connotations. What supports this presupposition is the abbreviation of the word "Deus" to the letters "eu"/ I which indicates the creation of man in God's image (Kac, "From ASCII To Cyperspace" 50). It is as if the poet/ artist implied that his digital aesthetic creativity is similar to God's power of creation. However, another reading hints to the viewer's interpretation of the political implication which the barcode image has. This shows that it is "a 'cheating' metapicture, ... whose real purpose is to reflect, not on pictures, but on the relation of pictures and words, both the way we speak of pictures and the way pictures "speak" to us" (Mitchell 66). Hence, the scattered numbers of the year 1964 mark the date of the Brazilian military coup which ends Goulart's presidency and features the turn to a military-authoritarian rule. Moreover, the letter foregrounding of $\mathrm{u} / \mathrm{s}$ in two of the abbreviated forms of the noun "Deus" can be symbolic of the U.S military intervention to support the success of the coup of $1964^{(8)}$. Though the barcode image does not reflect spiritual aspirations, the idea of military dictatorship and the existence of the fascist man can reflect a belief in religious absolutism. However,the researcher personally refutes this idea. 


\section{Poem as a Picture: Eduardo Kac's Digital Poetry and the Interdisciplinary}

Relationship Between Holographic Media and Literature

Staged in 1986 at the Brazil high-Tech exhibition, this gives voice to the role of the digital apparatus in expounding the aesthetic and political textures of "Deus". In this video poem the text-author/ Kac constitutes different sign symbols from the letters of the noun "Deus" and the numbers of the two years 1986 and 1964. The year 1986 is significant as it is when "Deus" has been performed on a Minitel computer. Moreover, the 1986 London's exhibition of Cybernetic Serendipity featuredadisplay of computerized arts and digital poetry, therefore, it was a remarkable year for the widespread of electronic media. Staging "Deus" on the screen of a minitel computer, this raises a discussion of the depth of the apparatus level. On the black screen of the minitel, videotext system, the viewer observes a white rectangle which soon turns into barcode images of different abbreviations for the noun "Deus". Bohn adds that "[f]irst "19" appears on the left and " 86 " on the right. Then a 6 is added to the first group: "19 6" and a 4 to the second group: " 486 ". Next, each of the vacant spaces receives a letter: "19D6" and "4S86". And finally an additional letter appears: "19D6E" and "U4S86" "(148). On the level of the transitive observable, this requires the viewer's cognitive interpretation of these fleeting media outlets. Hence, there is a built-in relationship between the minitel computer and the staged media which maintains an analysis of the barcode images. The digital context of "Deus" paves the road towards the veiwer's recognition of the main aesthetic texture of this visual videotext poem. This relates the level of the depth of the device to the process of media content analysis. Bootz stresses that "the multimedia event that appears on screen is only a transient observable state (a "transitoire observable" in French) that occurs while a computer is operating" ("The Problem of Form" 90). Analyzing "Deus" from the text-to-be-seen level, the viewer can understand Kac's tendency to form composites of letters and numbers as part of revolutionary aspirations of the futurist movement. Like the futurist poet Filippo Marinetti, Kac's barcode sequences show how the digital aesthetics shape poetry. Apart from the religious implications of 
the word "Deus," the viewer's subjective interpretations of the image emulatesthe spirit of Brazilian surrealism and the avant-garde movement.

Since the 1980s, Kac's experimentations with the art of holography create a number of holopoems ${ }^{(9)}$ which have peculiar aesthetic and digital features. Starting with an aspiration to go beyond the limits of paper, Kac'sholopoems stage three dimensional shapes in a manner which is psychologically similar to the free association of ideas in the stream of consciousness. The viewer has to relate the dispersed three dimensional words or numbers together in order to decode the meaning symbolism. Kac adds that "[i]n holopoetry, [design] immateriality refers to the fact that the verbal elements are organized in a space made of diffracted light" (129). Each time the observer indulges in a reading process of a holopoem, it restructures itself. As a form of experimental poetry, colour changeability, word transformations and anagrams create diverse viewpoints of each holopoem. Rotating graphics lead to different reading positions of a holopoem and thereby communicate changeable messages. Concerning the reading time of a holopoem, it is subject to a holographic universe $^{(10)}$. Kac points out that "holopoems are actually quadridimensional because they integrate dynamically the three dimensions of space with the added dimension of time. This is not the subjective time of the reader found in traditional texts, but a perceived time expressed in the holopoem itself" ("Holopoetry" 130). Motion graphics can move in all directions of the holographic space-time. The viewer's cognitive perception $^{(11)}$ is the process which maintains an analysis of each movable graphic and ascribes new meanings to the holographic discourse. In the holographic universe, time flows in reverse, so as to be in analogous symmetry with the viewer's head movements thus allowing him/her to make connections between the dynamic holographic images. Hence, the holographic display pertains to Mitchell's imagetext concept due to a union between graphics technology and words. 


\section{Poem as a Picture: Eduardo Kac's Digital Poetry and the Interdisciplinary}

Relationship Between Holographic Media and Literature

The structure of a holopoem and its sign systems pertain to a discussion of perceptual multistability and the role of the holographic apparatus. The researcher finds a mutual relationship between Mitchell's analysis of multistability and the reading of a holopoem which develops a binocular visual perception. The latter stands for the existence of two views at the same time like the rabbit-duck image. Hence, this accounts for the idea of colour change and how two colours can be perceived at once. Moreover, Kac believes that in holopoetry there is a possibility for parallax which is a "change in the direction of an object, caused by a change in observational position that provides a new line of sight" ("Holopoetry" 132). What constitutes the motion graphics that form the verbal/ visual discourse of digital holopoetry is the computer apparatus. Discussing sign symbolism of holopoetry, Kac mentions the use of fluid signs which acts as particles that form some of the holopoems. Fluid sings are verbal elements whose shapes are changeable. This shape change can be maintained by a union with other visual depictions or images. Therefore, their views enhance the phenomenon of multistability as they can be read differently. It is the researcher's role to analyze some of Kac'sholopoems which unite the features of Mitchell's "Other Pictures" with "Dialectical Images".

Kac's "Quando"?/ "When"? is a unique fractal holopoem written in Brazilian language, so as to relate the idea of fusional language to a poetry analysis in the context of Mitchell's metapictures. Working with the artist Ormeo Botelho, Kaccreates a distinguished holopoem, introducing the use of mathematical rules to the literary field. Fractal geometry helps Kac to design a fractal pattern which measures 360 degrees, displaying fragmented words that the viewer can read from any direction. The rotating fractal enhances binocular vision, therefore it can be considered as a multistable image which belongs to the second category of Mitchell's metapictures, "Dialectical Images". Marina Corrêa states that "Gestalt Theory, according to which "the whole is more than the sum of its parts" could be called into cause here [in "Quando"], not to 
approach cognition/ the intellect, but to question the viewer's physical identity" (9). Moreover, the fractal is the computer model which stages the overall depictions of verbal/ visual elements thus forming an imagetext composite. Its rotation which creates a multistable perception, also develops a bond between the main picture of the recurrent noun " $\mathrm{A}$ Luz"/ light and the other pictures/ words (Kac, "Holopoetry" 141). Through this structure of self-reference, the viewer can sort the imagetexts out, form sentences and reach conclusions about the poem's theme. This focus on the viewer's analysis of media displayed on a digital fractal gives readings of Bootz's procedural model. Based on the fractal geometry of Benoit Mandelbrot, the fractal holopoem "Quando?" realizes Kac's belief that quantum physics, math rules and the digital device can be part of and form a poetic experience:

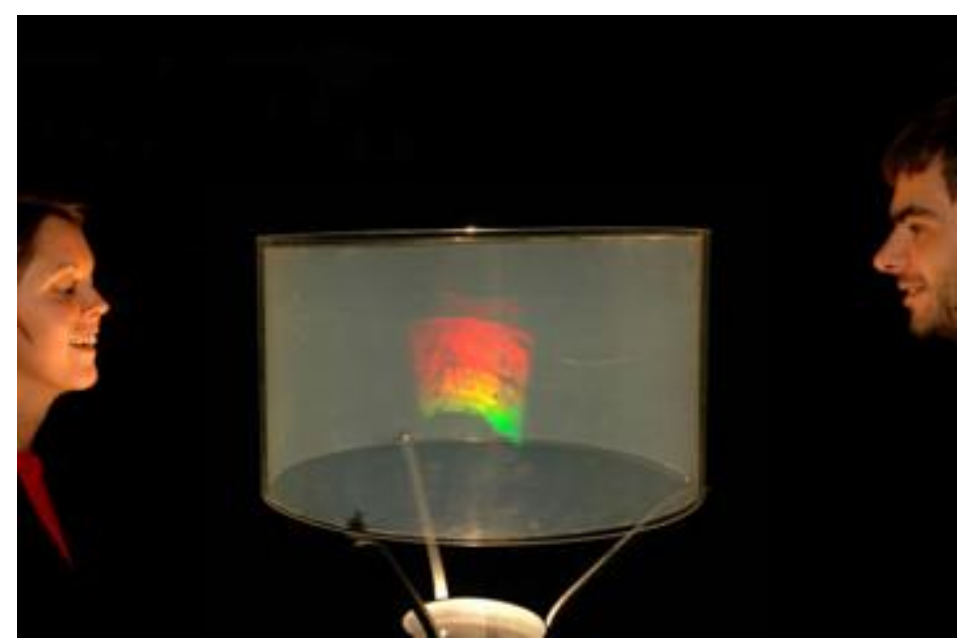

Fig. 4. A 40cm hologram and a fractal which measures 360 degrees designed between 1987/ 88 from: Kac, Eduardo. "Holopoetry". Mediapoetry, 1 April 2019, p. 141.

As a dialectical image, the fractal pattern of "Quando?" develops an analysis of time relativity. The researcher observes that the fractal dimensions of "Quando?" create perceptual illusions similar to that of thenecker cube; one of the multistable images discussed by Mitchell. The rotation of repetitive words/ imagetexts enhances a feeling of a deceptive perception which a multistable image gives. The fusional language of this fractal holopoem, which can be read in every direction, communicates the following: "A LUZ/ ILUDE/ A LENTE/ LENTA/ MENTE (the light/ 
deceives/ the lens/ slow/ ly); clockwise the text is A LENTE/ ILUDE/ A LUZ/ MENTE/ LENTA (the lens/ deceives/ the light/ slow/ mind). Other readings, just as valid as these, may arise, for instance, A LUZ/ MENTE/ LENTA/ A LENTE/ ILUDE(the light/ lies [i.e. tells lies]/ slow/ the lens/ deceives)" (Kac, "Holopoetry" 141). The choice of the interrogative title of the poem "When?" promotes the idea of word change, and reformulations of words which give the verbal discourse this multistable effect. Mitchell believes that " $[\mathrm{t}]$ he Duck-Rabbit, and multistable images in general, reveal the presence of a "mind's eye" roving around this storeroom, interpreting the pictures, seeing different aspects in them" (51). The viewer's binocular vision of words and his/ her subjective analysis contribute to the idea of time dilation. This relativity of time can be discussed in different levels. The time-line of man's subconscious thoughts, dreams and feelings is subjective and cannot be measured by a real-world time or a clock-defined time, therefore it may pertain to the holographic universe. Similarly, two viewers' perception of a mutlistable image/ fractal image can be different. Though some physicists believe that the space-time of a hologram is much the same as that of real universe, other philosophers like Tim Maudlin ${ }^{(12)}$ refute this claim. Hence, in 'Quando?' Kac asks whether there will be a possibility for an absolute time and space or not.

"Quando?" can also be taken as an example of the second form of Mitchell's first category of metapictures, "Other Pictures". Hence, "Quando?" commentson the art of holographic photography and nature of time. "Quando" elucidates that "the puzzling fact that ways of picturing the world are different in different times and places" (Mitchell 43). There are two possible argumentative readings of the imageword (13) "light"/ "ALUZ," which refers to other imagetexts and is symbolic of the art of photography. Laser photographs of the holograms are different from real photography and thereby the space-time of holography cannot be compared to that of man's universe. Another reading recommends that 
holographic imaging is analogous to the depictions of the remote universe. Hence, the holographic relativity pertains to that of the spacetime. This idea of general relativity and time deception echoes the perceptual illusions which the fractal pattern of "Quando?" maintains.

The use of computer graphics fractals and a vector fractal generator foreshadows the theme of relative time, maintains the mathematical poetics of "Quando?"/ "When?" and gives a complete picture of Bootz'sprocedural model. The text-author/ Kac chooses the word "ALUZ'/ light as a sign symbol which is indicative of the hologram atmosphere (141). The word stimulates a viewer/ reader's analysis which is inseparable from the digital device and the holographic universe. Bootz states that " $[a]$ profondeur de dispositif is applied as a filter by the cognitive strategy of reading or writing in order to decide what is the significance of the signs in the transient observable event that is produced during operation" ("The Problem of Form" 92). One of the main features of holopoetryiscolour change. The refraction of laser/ light, which the vector projector generates, stimulates the viewer's cognitive abilities to understand the main idea of the ephemeral digital media. From a transient observable level, the viewer understands that time is slower than the speed of light, therefore it is relative. Moreover, the rotating fractal, which is a computer graphic design, is connotative of the passage of time that is subject to the feelings of the observer ${ }^{(14)}$. Commenting on the digital environment of "Quando?," Kac elucidates that "[t]he monolithic fractal object rotates to accomplish almost two full turns inside the hologram. It thus widens the 360-degree space to nearly 720 degrees" ("Holopoetry" 141). In the case of the depth of the device paradigm, a viewer's analysis should involve an overview of the digital environment. Thus, the researcher conceives that the irregular shapes of the fractal dimensions are symbolic of this subjectivity of time. Even in the holographic universe of "Quando?" time proceeds unsystematically and moves in reverse, reflecting the main theme of the poem. Furthermore, there is an evidence of parallax which sets the matrix for the text to be 
seen level. Two viewers observing "Quando?" in opposite directions can have two subjective interpretations of the visual and verbal elements. Variations in perspectives and subjectivity of time perception drive Kac to ask when there will be an equation of time or not.

"Astray in Demios" (1992) is a holopoem whose lexical units maintain an interactive relationship between Mitchell's "Other Pictures" and "Dialectical Images". Kac'sholopem depicts a virtual tour to Demios which is one of the two tiny moons orbiting Mars. The yellow light ray and the light stages posit the two words "EERIE" and "MIST" as two fluid signs whose meaning is changeable (Kac, "Holopoetry" 147). This is because "[h]olographic poetry tries to exhibit the impossibility of an absolute textual structure; it attempts to create verbal patterns with disturbances that magnify small changes in meaning according to the perceptual inquiry of the reader" (Kac, "Holopoetry" 134). Transformation of sings and the phenomenon of parallax enhance a multistable perception and develop an analysis of multistable images. Taking "EERIE" as a picture, the researcher observes an indication of self-reference to another picture "MIST". Holographic vector display creates views of broken glass shapes which maintain the idea of multistability. The circle of light can be seen either as a symbolic picture of Demios or a panoramic view of Mars. "Astray in Demios" can also be considered as a space poem, reflecting the relationship between astronomy and poetry whose poetic lexis are fluid signs which constitute the concept of imagetext: 


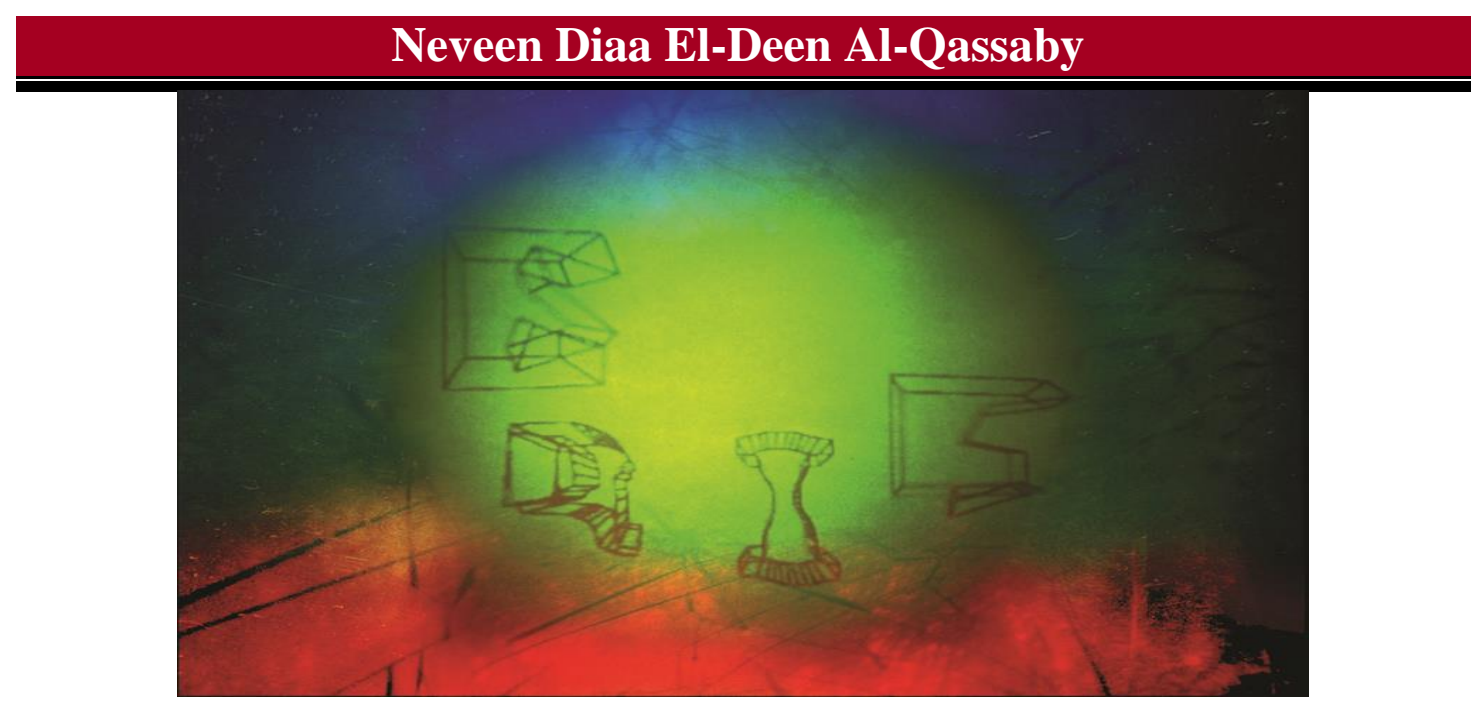

Fig. 5. A holographic display of Demios shown at the Museum of Holography in Chicago in 1992 from: Kac, Eduardo. "Holopoetry". Mediapoetry, 1 April 2019, p. 149.

Fluid sings and the holographic portrayal of realistic planet models expound a poetry analysis of metapictures. Mitchell believes that the "destabilizing of identity is to some extent a phenomenological issue, a transaction between pictures and observers activated by the internal structural effects of multistability" (57). In "Astray in Demios," Kac's use of fluid metamorphosis so as to amalgamate fluid letterforms/ verbal elements with abstract shapes is a process which creates new meanings. The use of abstract alphabet vectors of "EERIE" and "MIST" and their unity shows how the phonetic matter conveys meaning. This fluid metamorphosis of imagetexts/ verbal and visual elements constitutesmultitable images. Displacing the letter shapes is a transitory stage which precedes the complete change of temporal typography thus activating the viewer's multistable perception of the meaningless verbal forms. Barbara Brownie discusses this idea of metamorphosis of fluid sings. She comments that "[i]n this kind of transformation, letterforms are treated as malleable. Their contours are elastic, permitting total transformation of the form so that it evolves, as if organically, into something else ..." (Brownie 162). The viewer should not be concerned with a semantic analysis of the visual transformations, however the unity between "EERIE" and "MIST" can be phonetically understood as mystery, mystical and mysterious (Kac,"Holopoetry"149). He/ she may realize that the imaginary visit to Demios can be indicative of a mystical 
experience of poetry. Even the holographic structures of the moon demios have a mystical significance. Another observer will understand that Kac can create mysterious holopoems which are similar to the mysteries of Mars. Furthermore, the broken glass effect on the holographic models of Demioscauses a binocular vision or multistablephenomena. The observer is the one who can determine whether he/ she views letterforms or holographic shapes of Demios.

In "Astray in Demios," holographic shapes/ transient letterforms constitute two pictures; one of them is "EERIE" which refers to another one "MIST".Kac introduces the first one as if it were an adjective and the second as a noun, therefore, the researcher observes that the two pictures appear to be different from each other. The dialectical readings of this holopoem/ metapicture give an account about the art of photography. Mitchell stresses that it "is a metapicture that refers, not to itself, but to [another picture] a class of pictures that are generally understood to be different in kind from itself" (42). The first argumentative perspective assumes that the aesthetics of holography creates holographic replica of Demios which is much similar to reality. A second dialectical analysis argues that holograms cannot be as accurate as the planetry images taken by a space telescope like Hubble. However, the two readings prove the evolution of photography which varies between the art of holography and space imaging. Depicting a virtual tour to Demios, the holographic poem introduces the use of holography to the poetic field, thus giving implications about the incompleteness of life and man.

The holographic environment of "Astray in Demios" gives manifestations of Bootz's procedural model. The two sign symbols/ pictures introduced by the text-author are "EERIE" and "MIST". The fluidity of the alphabets further enhances the parallax effect and points to different interpretations of the holopoem. Hence, the same letterform/ holographic image is viewed differenty by two observers according to his/ her position. Besides causing a multistableperception, motion 


\section{Neveen Diaa El-Deen Al-Qassaby}

parallax sustains displacement of the supposed adjective and noun in the poem. Changing the position of the adjective and the noun leads to a difference in the viewed impressions. Kacstates that "[a]s the viewer moves relative to the piece, he or she perceives that each line that renders the graphic configuration of each letter starts to actually move in threedimensional space ... . The shifting of grammatical forms occurs not through syntactical dislocations in a stanza, but through a typographic metamorphosis that takes place outside syntax" ("Holopoetry" 148). An analysis of the fleeting multimedia content/ fluid signs should be done in relation to the digital environment and the function of digital device. This pertains to a brief discussion of the trasitive observable and the depth of the device levels. Kac's use of a multicolour computer holographic system projects computer-generated holograms of letterforms that metamorphize into crater curves for Demios and shaped objects on Mars. Moreover, the holographic background gives an impression of a real like atmosphere of space. Analyzing the verbal and visual elements, the researcher realizes Kac's main message. The latter stresses that the use of holography opens up new horizons for the poetic experience in the same manner of space discoveries which maintain the possibility of life on other planets. On the level of the text-to-be seen, the interplay between the adjective and the noun develops diverse viewpoints of the holopoem. Basically, the adjective "EERIE" can be a phonetic indication of rarefied. The viewer may believe that this holopoem's theme, which is the rarefied atmosphere of Mars, can evoke the idea of religious ecstasies and mysticism in poetry.

Discussing the main features of electronic literature, the researcher analyzes selected pictures/ digital poems of Eduardo Kac which are taken as different forms of metapictures. Hayles introduces the reader/ researcher to the major genres of this computer-based literature, tracing different stages in its history. The paper shows an interdependent bond between the aesthetics of poetry and other fields of study like fractal geometry. Kac realizes this interdisciplinary approach in his diverse forms of digital poetry,such as holopoetry, biopoetry and hyper poetry. 
For instance, in "Genesis," the poet/ artist introduces the field of genetic engineering to the poetic experience. The researcher gives an overview of a number of Kac's media poems, so as to highlight some of the thematic connotations which they can raise. Relating selected digital poems of Kac to Mitchell's Picture Theory, the researcher expounds the constructive aspects of his different categories of metapictures. Mitchell believes that what turns a picture into a metapicture is its ability to give extra information about itself and to comment on the mechanisms of picturing. $\mathrm{He}$ analyses four categories of metapictures. In the first category entitled as "The Picture Itself," he gives the example of Steinberg's The Spiral to explain how a picture can be self-analytical. As for the second form of self-referential pictures, "Other Pictures," Mitchell chooses Alain's painting "Egyptian Life Class" to elucidate it. It shows how a picture which makes reference to another one different from it can give reflections on the art of photography. Discussing the "Dialectical Images," the iconic painting of Joseph Jastrow's "The Duck-Rabbit" illustrates the phenomenon of perceptual illusions. Velázquez's Las Meninas is "A Meta-metapicture," which alludes to the idea of visual representation and focuses on a dislocation of the viewer's position. Giving the example of Magritte's Les Trahison des Images/ The Treachery of Images, the researcher elucidates the final category of "Talking Metapictures". The latter stands for the complete separation of verbal and visual elements or audible and visual representations. In order to further expound the discourse on metapictures, the researcher overviews thoughts of a number of scholars and art historians, such as Sunil Manghani, Bruno Trentini and Brain Kim Stefans.

The researcher adheres to Bootz's procedural model in her critical perspectives on the selected poems. On the level of the text to be seen, a viewer's subjective analysis of the media content should be based on his/ her reading of the encrypted message in the text. As for the two levels of the depth of the device and transitive observable, they complement each other. This is because a good recognition of the digital device and digital context stimulates the viewer's cognitive perception of the ephemerial 


\section{Neveen Diaa El-Deen Al-Qassaby}

media content. For instance, the structure of the interactive poem "Letter," which reflects the shape of vector circles, can be connotative of revising one's thoughts and memories. As for the videotext poem "Deus," the use of a minitel computer helps Kac to display different barcode images which have political and aesthetic connotations. Moreover, in the fractal holopoem "Quando?," the computer-generated fractals reflect on the nature of time and show an interplay between mathematics/ fractal geometry and poetry. While, in the holopoem "Astray in Demios" the use of a multicolour computer holographic system creates a projection of fluid signs/ transient topography and reveals that the virtual holograms of this moon can express a mystical experience thus turning a virtual process of space imaging into a poetic experience. The researcher supports her critical analysis of the selected poems/ pictures with a number of scholarly research studies. 


\section{References}

Ancell, Matthew. "The Theology of Painting: Picturing Philosophy in Velázquez's Las Meninas". The Comparatist, vol. 37, no. 1, May 2013, pp. 156-168. Project Muse, https://www.academia.edu/ 3547273/TheTheology. Accessed 3 April 2019.

Andersen, Rune Saugmann. "Meta-mediation, Visual Agency and Documentarist Reflexivity in Conflict Film: Burma VJ meets Burke + Norfolk". Documenting World Politics: A Critical Companion to IR and Non-Fiction Film. Edited by Munster, Rens Van and Casper Sylvest. Routledge, 2015, pp. 150-165.

Bargetz, Brigitte. "Figuring Ambivalence, Capturing the political: An Everyday Perspective". Multistable Figures: On the Critical Potentials of Ir/ Reversible Aspect-Seeing. Edited by Holzhey, Christoph F.E. Cultural Inquiry, 2014. 7-265.

Bohn, Willard. "Digital Poetry". Fairleigh Dickinson University Press. 2011, pp. 141-159.

Bohn, Willard. "Eyesight and Insight". Fairleigh Dickinson University Press. 2011. pp. 160-162.

Bohn, Willard. "The Word Made Flesh". Fairleigh Dickinson University Press. 2011. pp. 13-18.

Bohn, Willard. Reading Visual Poetry. Fairleigh Dickinson University Press. 2011. 5-176.

Bootz, Philippe. "Programmed Digital Poetry: A Media Art?". Ljubljana, vol. 36, no. 1, January 2013, pp. 41-60, https://www.dlib.si/stream/ URN:NBN:S1:doc-FHSLYCCQ/...72e 7 .../PDF. Accessed 12 April 2019.

Bootz, Philippe. "The Problem of Form: Transitoire Observable, a Laboratory for Emergent Programmed Art". The Aesthetics of Net Literature: Writing, Reading and Playing in Programmable Media. Edited by Gendolla, Peter and Jörgen Schäfer. Transcript Verlag, 2007, pp. 89106.

Brownie, Barbra. "Fluid Typography: Transforming Letterforms in Television Idents". Arts and the Market, vol. 5, no. 2, 2015, pp. 154-167, https://www.researchgate. net/profile/Barbara Brownie. Accessed 18 April 2019.

Castrillo, Carolina Fernandez. "Lyric Simultaneities: From "Words in Freedom" to Holopoetry". Cultura: International Journal of Philosophy of Culture and Axiology, vol. 13, no. 2, 2016, pp. 125-136. 


\section{Neveen Diaa El-Deen Al-Qassaby}

https://www.ingentaconnect. com/contentone/p19. Accessed 20 April 2019.

Clüver, Claus. " 'Transgenic Art': The Biopoetry of Eduardo Kac”. Media Borders, Multimodality and Intermediality, edited by Lars Elleström, Palgrave Macmillan, 2010. Springer Link, https://download.Springer.com/static/pdf/ 183/bok\%253A978-0-23027520-1.pdf?originUr1-l=http\%3A\%2F . Accessed 14 April 2019.

Daniel, g. Reginald. "The Brazilian Path Less Traveled: Contesting the Ternary Racial Project". Race and Multimodality in Brazil and the United State: Converging Paths? The Pennsylvania State University, 2006, pp. 53-84.

Deac, Ioana - Eliza. "New Meanings of Poetry in Eduardo Kac's Poems". Cybertext Yearbook, 2010, pp.1-16, https://cybertext.hum.jyu.fi/articles/139.pdf. Accessed10 April 2019.

Emerson, Caryl and InessaMedzhibovskaya. "Dostoevsky, Tolestory, Bakhtin on Art and Immortality". Critical Theory in Russia and the West. Edited by Renfrew, Alastair and TihanovGalin. Routledge, 2010, pp. viii-215.

F.E.Holzhey,Christoph,editor.Multistable Figures: On the Critical Potentials of Ir/Reversible AspectSeeing.CulturalInquiry,VERLAGTURIA+KANT,2014,pp.7-265.

GayanaJurkevich. "Azorins' classics: El Greco and Velázquez in Essays and Fiction". In Pursuit of the Natural Sign: A Zorin and the Poetics of Ekphrasis. Bucknell University Press, 1999, pp. 68-94.

Hayles, Katherine. Electronic Literature: New Horizons for the Literary. University of Notre Dame Press, 2008. The Tactile Word, https://tactileword. files.wordpress.com. Accessed 13 April 2019.

Helps Word-Studies. Bible Hub, http://biblehub.com/Greek/3309.htm. Accessed 19 Oct.2019.

Kac Eduardo and Ormeo Botelho. "Holopetry and Fractal Holopoetry: Digital Holography as an Art Medium". Leonardo, vol. 22, no. 3-4, 1989, pp. 397-402, arteca.mit.edu/journal/10.1162/leon.1989.22.3-4.3. Accessed 13 April 2019.

Kac, Eduardo, editor. "Biopoetry". Media Poetry. An International Anthology. Intellect Books, The University of Chicago Press, 2007, https://elmcip.net/.../ Kac_eduardo_ed_media_poetry_ an_internati.... Accessed 1 April 2019.

Kac, Eduardo, editor. "From ASCII to Cyberspace: a Trajectory in Digital Poetry". Media Poetry. An International Anthology. Intellect Books, The University of Chicago Press, 2007, https://elmcip.net/.../Kac eduardo_ed media_poetry_an_internati....

Accessed 1 April 2019. 
Poem as a Picture: Eduardo Kac's Digital Poetry and the Interdisciplinary Relationship Between Holographic Media and Literature

Kac, Eduardo, editor. "Holopoetry". Media Poetry. An International Anthology. Intellect Books, The University of Chicago Press, 2007, https://elmcip.net/.../ Kac eduardo_ed media poetry an internati.... Accessed 1 April 2019.

Kac, Eduardo, editor. "Introduction". Media Poetry. An International Anthology. Intellect Books, The University of Chicago Press, 2007, https://elmcip.net/.../ Kac eduardo ed media poetry an internati.... Accessed 1 April 2019.

Kac, Eduardo. "Holopoetry and Hyperpoetry". The Pictured Word: Word and Image Interactions 2. Edited by heusser, Martin, Claus Clüver and etl. Rodopi, 1998, pp. 169-182.

Ledesma, Eduardo. Radical Poetry: Aesthetics, Politics, Technology and the Ibero-American. Avant-Gardes, 1900-2015. Suny Press, 2016. Vii-331.

Lennon, Brian. "Screening a Digital Visual Poetics". Mediapoetry. An International Anthology, edited by Eduardo Kac, Intellect Books, The University of Chicago Press, 2007. ELMCIP, https://elmcip.net/.../Kac eduardo_ed_media_poetry an internati.... Accessed 1 April 2019.

Manghani, Sunil. Image Studies: Theory and Practice. Routledge, 2013. Vii263.

Martinengo, Alberto. "From the Linguistic Turn to the Pictorial TurnHermeneutics Facing the Third Copernican Revolution". Proceedings of the European Society for Aesthetics, vol. 5, no. 1, 2013, pp. 302-312. https://www.eurosa.org. Accessed 7 April 2019.

Mitchell, WJT. "Metapictures". Picture Theory: Essays on Verbal and Visual Representation. University of Chicago press, 1994. IX-445.

Mitchell, WJT. "The Pictorial Turn". Picture Theory: Essays on Verbal and Visual Representation. University of Chicago press, 1994. IX-445.

Mitchell, WJT. Picture Theory: Essays on Verbal and Visual Representation. University of Chicago press, 1994. IX-445.

Old/ New Testament Greek Lexical Dictionary.StudyLight.ORG,https://www.studylight.org/lexicons/greek/ 3309.htm.Accessed 190ct.2019.

Osthoff, Simone. "From Mail Art to Telepresence: Communication at a Distance in the Works of Paulo Bruscky and Eduardo Kac"., www.personal.psu.edu/ sx011/publications/from\%20Mai/\%20Art\%20to\%20Telepresence.pdf. Accessed 7 April 2019. 


\section{Neveen Diaa El-Deen Al-Qassaby}

Stefans, Brian Kim. "The New Commodity: Technicity and Poetic Form". Word Toys: Poetry and Technics. The University of Alabama Press, 2017. Vii-333.

T. Coates, Andrew. What is Protestant Art? Brill, 2017. 1-133.

Tolstoy, Leo. War and Peace. England, Penguin Classics, 1982.

Trentini, Bruno. "The Meta as an Aesthetic Category". Journal of Aesthetics and Culture, vol. 6, no. 1, April 2014, pp. 1-9, https://tandfonline.com. Accessed 5 April 2019.

White, John J. "Perspective in Experimental Shaped Poetry: A Semiotic Approach". From Sign to Signing: Iconicity in Language and Literature 3. Edited by G. Müller, Wolfgang and Olga Fischer. John Benjamins Publishing Company, 2002, pp. 105-128.

(1) Interactive poetry urges the participation of the reader/viewer in the literary, digital experience. Holopoetry blends the use of holographic technology and standard language. Kac's main innovative contribution is biopoetry which relates the science of genes to the poetic experience. Finally, a hyper poem is based on cyber media and should be staged on a computer system.

(2) See p. 89 in Mitchell's Picture Theory, and the researcher's discussion of the three different relationships between images and texts expounded in "Beyond Comparison".

$\left(^{3}\right)$ For further information about the poetic language of the media apparatus, and the visual poetics of the digital image, see Frosh, Paul .ThePoetics of Digital Media. Polity Press, 2019, pp. vi-215.

$\left.{ }^{4}\right)$ For further information about how words become part of the artistic process in the present culture, see Petry, Michael.The Word is Art. Thames \& Hudson, 2018, pp. 288.

$\left({ }^{5}\right)$ See Moore, Michael. "On The Signification of Walls in Verbal and Visual Art". Leonardo, vol. 12, no. 4, Autum 1979, pp. 311-313, https://www.jstor.org/stable/1573896? seq=1. Accessed 21 April 2019.

$\left.{ }^{6}{ }^{6}\right)$ See Huston, Mathew. "This 'mind-reading' algorithm can decode the pictures in your head". Science, January 10, 2018, https://www.sciencemag.org. Accessed 17 April 2019.

(7) For further information about Parnassian Poetry the reader can review Nist, John The Modernist Movement inBrazil:A literary Study (1967). University of Texas Press, 1967,pp.223.

$\left({ }^{8}\right)$ See Spektor, Matias. "The United States and the 1964 Brazilian Military Coup". Oxford Research Encyclopedia of Latin American History. Oxford University Press, 2018, pp.1-19, https://www.researchgate.net/profile/MatiasSpektor. Accessed 15 April 2019.

${ }^{9}$ ) For a complete chart of the diverse genres of holopoetry and the different technological techniques used in the production of a holopoem, seeIsik, Vildan."Holographic Art Jargon”. ElektronikSosyalBilimlerDergisi, vol. 15, issue 59, Autumn 2016, pp. 1403-1420, https://dergipark.org.tr/en/download/articlefile/z Accessed 16 April 2019. 
Poem as a Picture: Eduardo Kac's Digital Poetry and the Interdisciplinary Relationship Between Holographic Media and Literature

$\left({ }^{10}\right)$ See J. Richardson, Martin and John D. Wiltshire. The Hologram: Principles and Techniques. Wiely-IEEE Press, 2018, pp. xi-303.

$\left({ }^{11}\right)$.See B. Thompson, William, et al., Visual Perception from A Computer Graphics Perspective. CRC Press, 2011, pp. viii-519.

(12) See Maudlin, Tim. Philosophy of Physics Space and Time. Princeton University Press, 2012, pp. ix-181.

$\left({ }^{13}\right)$ The concept imageword is used by Kristie $S$. Fleckenstein in her book.SeeFleckenstein, Kristie S. Embodied Literacies: Imageword and a Poetics of Teaching. Southern Illinois University Press, 2003, pp. xi-207.

$\left({ }^{14}\right)$ See Tanaka, R. \&Yotsumoto, Y. "Passage of Time Judgments is Relative to Temporal Expectation". Frontiers in Psychology, vol. 8, $187: 2017$, https://www.ncbi.n/m.nih.gov/pmc/articles/PMC5. Accessed 17 April 2019. 